\title{
Effect of Calcium Addition on the Rolled Microstructure of a Kind of HSLA Steel
}

\author{
Yan Liu, ${ }^{1,}$, Kai Wang ${ }^{2, b}$, Jianming Wang ${ }^{2, c}$ and Chunlin $\mathrm{He}^{1, \mathrm{~d}}$ \\ ${ }^{1}$ The Liaoning Provincial Key Laboratory of Advanced Materials \& Preparation Technology, \\ Shenyang University, Shenyang, 110044, China \\ ${ }^{2}$ School of Mechanical Engineering, Shenyang University, Shenyang 110044, China \\ aliuyanneu@163.com, bwkai1991@foxmail.com, 'wjmlucky1979@163.com, 'ccllhhe@126.com
}

Keywords: calcium, rolled microstructure, HSLA steel, bainite, strength and toughness

Abstract. The rapid development of the large steel structure brings a great opportunity for steelmaking industry. The steel plates not only have the strength and toughness but also can withstand the high energy input welding. Using the calcium oxide of high melting-point and high stability to pin the grain boundaries is an effective method to improve the welding performance of the structure steel. Calcium was added into molten steel in the form of Ca-Si alloy using the special process in the experiment. A kind of HSLA steel containing $\mathrm{Ca}$ was prepared by means of the vacuum induction melting and controlled rolling and controlled cooling experiments. The effect of calcium addition on the rolled microstructure of HSLA steel was analysed. The results show that the addition of $\mathrm{Ca}$ elements has a significant effect on the microstructure of the rolled steel. The rolled microstructure of the experimental steel consists of polygonal ferrite and granular bainite and small amount of pearlite. The emergence of bainite is favorable to the strength and toughness of the experimental steel.

\section{Introduction}

The rapid development of the large steel structure brings a great opportunity for steelmaking industry. However, as the design requirements improve and the manufacturing technology of the steel structure advances, the requirements for the performance of steel plates which are used to fabricate the steel structure also improve continuously [1-3]. The steel plates not only have the strength and toughness but also can withstand the high energy input welding [4-6]. Using the calcium oxide of high melting-point and high stability to pin the grain boundaries is an effective method to improve the welding performance of the structure steel. If this method combines with TMCP (Thermo Mechanical Control Process), we can get the high heat input welding high-strength low alloy (HSLA) steel, which has good toughness and weldability.

Calcium was added into molten steel in the form of $\mathrm{Ca}-\mathrm{Si}$ alloy using the special process in the experiment. A kind of HSLA steel containing $\mathrm{Ca}$ was prepared by means of the vacuum induction melting experiments and controlled rolling and controlled cooling experiments, and the effect of calcium addition on the rolled microstructure of the HSLA steel was analysed. The study can provide a reliable theoretical basis and technical support for the development and application of high heat input welding HSLA steel The study can reduce production costs and save social resources effectively. The research results can transform into productivity and create a new growth point for the national economy.

\section{Experiments}

Experimental Materials. A kind of HSLA steel was designed in this experiment. The components of the steel were obtained by smelting pure iron and adding the corresponding alloy. The components of pure iron and main alloy were shown in Table 1.

Calcium was added in the form of $\mathrm{Ca}-\mathrm{Si}$ alloy. Other alloys included electrolytic manganese (99.9\%), ferrovanadium (78.6\%), ferrotitanium (99\%), ferroniobium (65.6\%), ferronickel (78.6\%), ferrochromium $(85.5 \%)$ and molybdenum $(76.3 \%)$. 
Table 1 Components of pure iron and main alloys (wt $\%)$

\begin{tabular}{ccccccccccccc}
\hline Alloy & $\mathrm{C}$ & $\mathrm{Si}$ & $\mathrm{Mn}$ & $\mathrm{P}$ & $\mathrm{S}$ & $\mathrm{Al}$ & $\mathrm{Fe}$ & $\mathrm{Ca}$ & $\mathrm{Mg}$ & $\mathrm{Zr}$ & $\mathrm{Ni}$ & $\mathrm{Cu}$ \\
\hline $\begin{array}{c}\text { Pure } \\
\text { iron }\end{array}$ & 0.0013 & 0.01 & 0.05 & 0.007 & 0.0044 & 0.0013 & 92.6 & $/$ & $/$ & $/$ & $/$ & $/$ \\
$\mathrm{Fe}-\mathrm{Si}$ & 0.024 & 78.96 & 0.058 & 0.0093 & 0.0037 & 0.24 & 20.24 & $/$ & $/$ & $/$ & $/$ & 0.049 \\
$\mathrm{Si}-\mathrm{Ca}$ & 0.13 & 66 & $/$ & 2.6 & $/$ & 0.15 & $/$ & 31 & $/$ & $/$ & $/$ & 12 \\
\hline
\end{tabular}

We designed a kind of HSLA steel, based on the above principle and absorbing predecessors's research experiences. The BJ-VIM-5 vacuum induction melting furnace was used in the smelting experiment of HSLA steel. The $\mathrm{MgO}$ crucible was used in the test. The four furnaces in the test were accomplished in the order of no calcium addition, $1 \mathrm{wt} \% \mathrm{Ca}$ addition, $3 \mathrm{wt} \% \mathrm{Ca}$ addition and $5 \mathrm{wt} \% \mathrm{Ca}$ addition.

Process of Rolling and Cooling. The experiment of rolling and cooling used the $\Phi 450$ hot rolling machine group and controlling cooling system. The start rolling temperature was $1200^{\circ} \mathrm{C}$. The fourth pass rolling temperature was controlled at about $950^{\circ} \mathrm{C} \sim \mathrm{Ar} 3$, and the final rolling temperature was controlled at $950 \sim 700^{\circ} \mathrm{C}$. After rolling, the temperature was reduced to $380^{\circ} \mathrm{C}$ by water cooling, then air cooling [7]. The rolling temperature of the pass steel plate was measured by the infrared thermometer, and the cooling time was determined by the stopwatch, so the cooling rate could be calculated. The rolling process parameters of the experimental steel were shown in Table 2, and the cooling process parameters were shown in Table 3.

Table 2 Rolling process parameters of experimental steel

\begin{tabular}{cccc}
\hline Experimental steel & $\begin{array}{c}\text { Start rolling temperature } \\
\left({ }^{\circ} \mathrm{C}\right)\end{array}$ & $\begin{array}{c}\text { Final rolling temperature } \\
\left({ }^{\circ} \mathrm{C}\right)\end{array}$ & $\begin{array}{c}\text { Thickness after rolling } \\
(\mathrm{mm})\end{array}$ \\
\hline $\mathrm{Ca} 1 \%$ & 1200 & 810 & 12.1 \\
$\mathrm{Ca} \%$ & 1190 & 790 & 12 \\
$\mathrm{Ca} 5 \%$ & 1230 & 850 & 12.2 \\
The original steel & 1950 & 770 & 11.9 \\
\hline
\end{tabular}

Table 3 Cooling process parameters of experimental steel

\begin{tabular}{cccc}
\hline Experimental steel & $\begin{array}{c}\text { Start cooling temperature } \\
\left({ }^{\circ} \mathrm{C}\right)\end{array}$ & $\begin{array}{c}\text { Final cooling temperature } \\
\left({ }^{\circ} \mathrm{C}\right)\end{array}$ & Cooling rate $\left({ }^{\circ} \mathrm{C} \cdot \mathrm{s}^{-1}\right)$ \\
\hline $\mathrm{Ca} 1 \%$ & 800 & 375 & 19.6 \\
$\mathrm{Ca} \%$ & 780 & 355 & 23.1 \\
$\mathrm{Ca} \% \%$ & 830 & 190 & 25.6 \\
The original steel & 750 & 380 & 35.3 \\
\hline
\end{tabular}

\section{Effect of Calcium Addition on the Rolled Microstructure of the HSLA Steel}

The prepared metallographic samples zoomed in 200 and 500 times were respectively observed using the OLYMPUS-CK40M optical metallographic microscope. The diagrams of rolled microstructure of the HSLA steel were obtained.

The contrast diagrams of the rolled microstructure at the bottom of the samples of the HSLA steel were shown in Fig. 1 (a-d), including no calcium addition (the original steel), $1 \mathrm{wt} \% \mathrm{Ca}$ addition, $3 \mathrm{wt} \% \mathrm{Ca}$ addition and $5 \mathrm{wt} \% \mathrm{Ca}$ addition.

The microstructures that often can be found in the common steel are bainite, martensite, pearlite, ferrite, and so on. We can find that there are some differences in the microstructure among each experimental steel. The observation results of rolled microstructure were tabulated and shown in Table 4. 


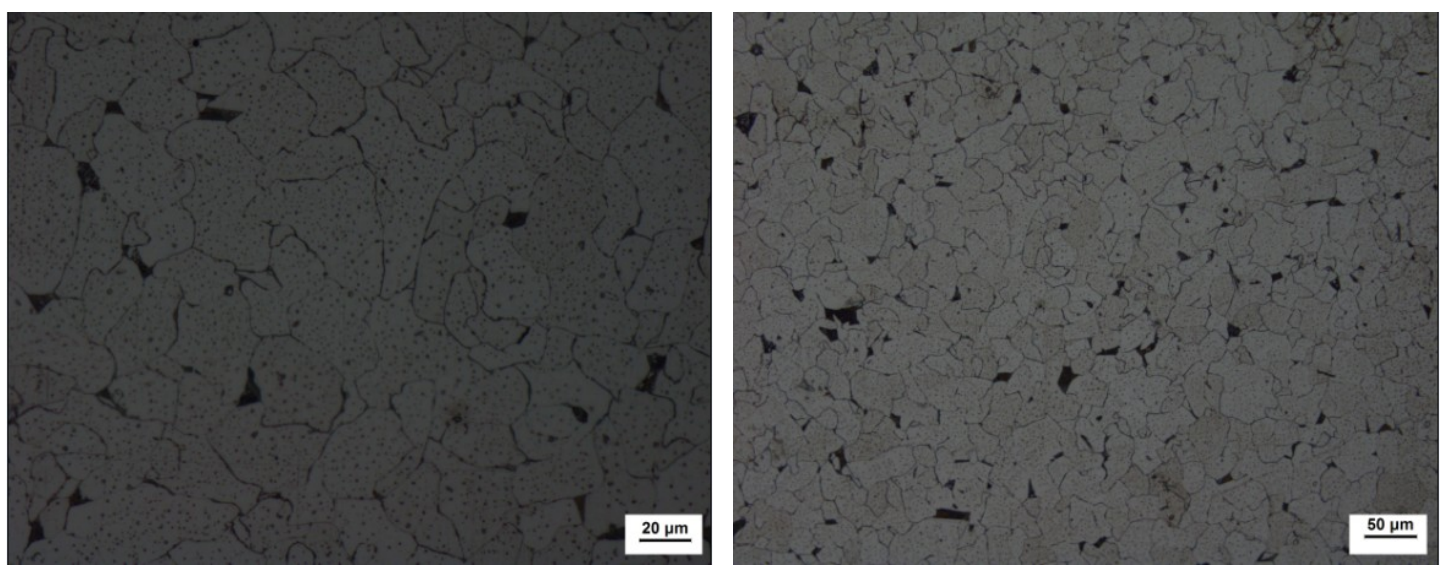

a. the rolled metallographic microstructure of the original steel

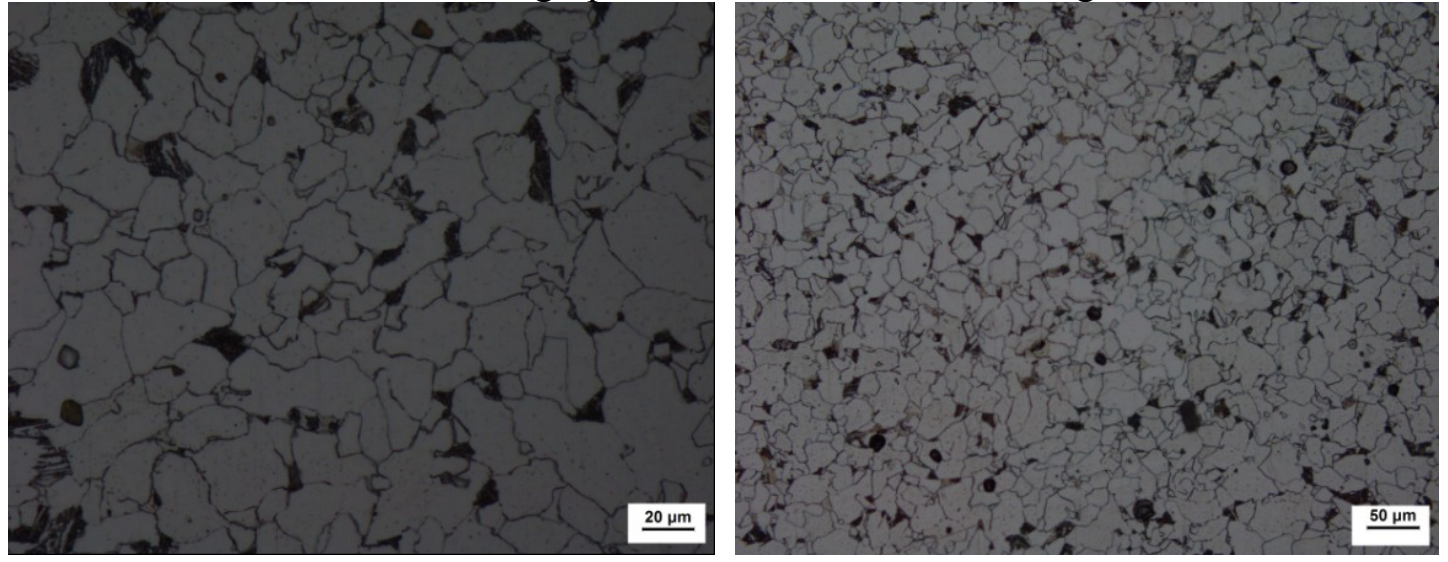

b. the rolled metallographic microstructure of the experimental steel containing $1 \mathrm{wt} \% \mathrm{Ca}$

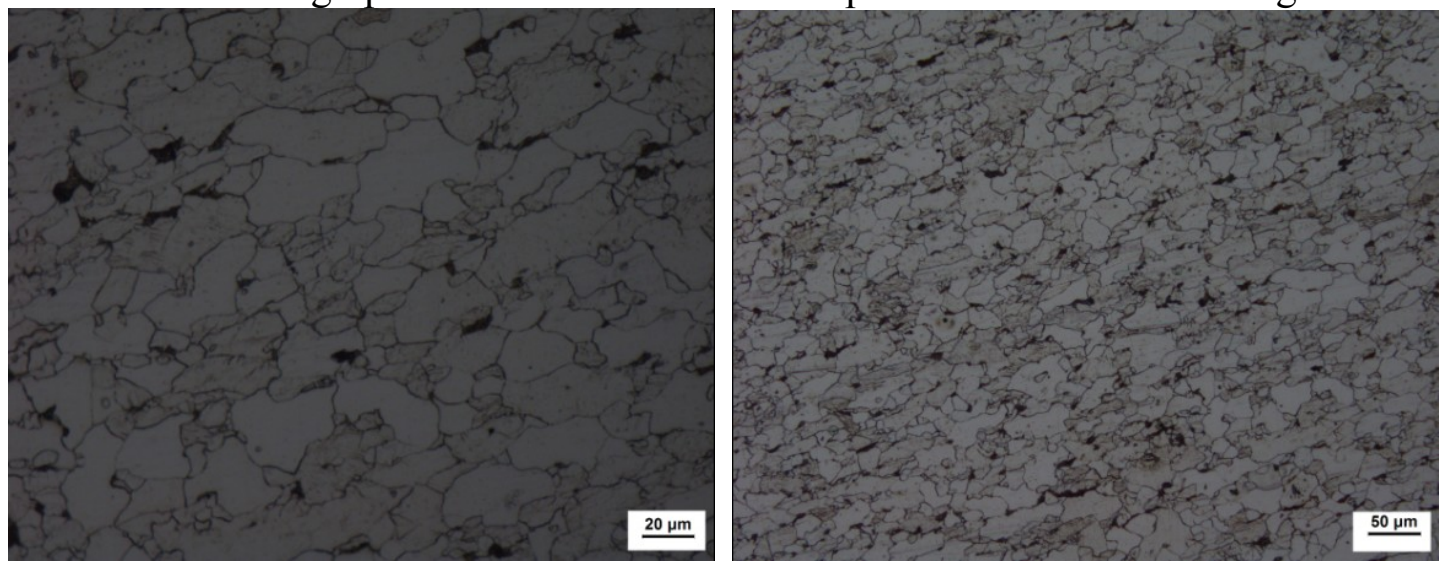

c. the rolled metallographic microstructure of the experimental steel containing $3 \mathrm{wt} \% \mathrm{Ca}$

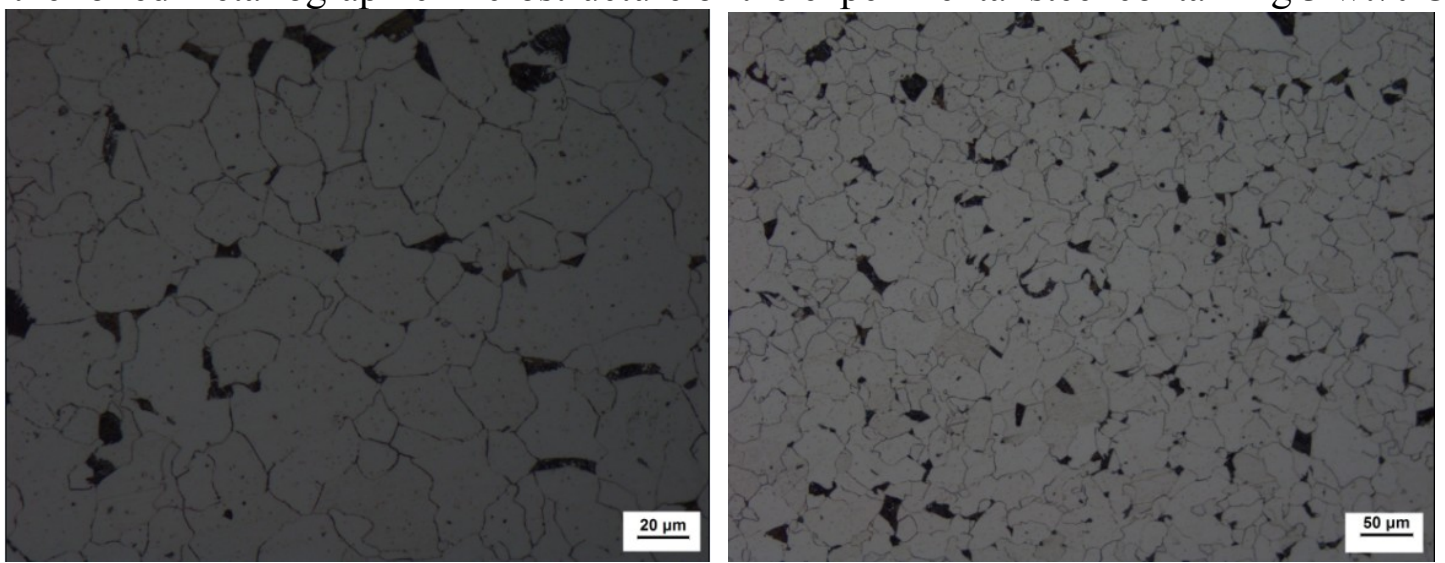

d. the rolled metallographic microstructure of the experimental steel containing $5 \mathrm{wt} \% \mathrm{Ca}$

Fig. 1 Rolled microstructure comparison diagrams of each sample containing $\mathrm{Ca}$ 
Table 4 Microstructure observation results of rolled steel containing $\mathrm{Ca}$

\begin{tabular}{cc}
\hline Experimental steel & The observation results of microstructure \\
\hline The original steel & polygonal ferrite + small amount of quasi-polygonal ferrite + small \\
amount of pearlite & polygonal ferrite + quasi-polygonal ferrite + small amount of pearlite + \\
sa $1 \%$ & polygonal ferrite + moderate quasi-polygonal ferrite + small amount of \\
pa3 $\%$ & pearlite + extremely small amount of bainite \\
$\mathrm{Ca} 5 \%$ & polygonal ferrite + quasi-polygonal ferrite + small amount of pearlite
\end{tabular}

From the above analysis results, it can be seen that the samples are rolled after melting and austenitizing, and the cast microstructure has been changed after rolling and the deformed austenite. The rolled microstructure of the experimental steel consists of polygonal ferrite and granular bainite and small amount of pearlite. For the experimental steel of different compositions and contents, the proportion of bainite and ferrite has a certain gap, which will lead to some differences in mechanical properties.

\section{Conclusions}

Calcium was added into molten steel in the form of $\mathrm{Ca}-\mathrm{Si}$ alloy using the special process in the experiment. A kind of HSLA steel containing $\mathrm{Ca}$ was prepared by means of the vacuum induction melting experiments and controlled rolling and controlled cooling experiments, and the effect of calcium addition on the rolled microstructure of the HSLA steel was analysed.

(1) The samples are rolled after melting and austenitizing, and the cast microstructure has been changed after rolling and the deformed austenite.

(2) The addition of $\mathrm{Ca}$ elements has a significant effect on the microstructure of the rolled steel. The rolled microstructure of the experimental steel consists of polygonal ferrite and granular bainite and small amount of pearlite. The emergence of bainite is favorable to the strength and toughness of the experimental steel.

(3) For the experimental steel of different compositions and contents, the proportion of bainite and ferrite has a certain gap, which will lead to some differences in mechanical properties.

\section{Acknowledgments}

This work was supported by the Liaoning Province Natural Science Fund Project (No. 2014020097), the Project for Liaoning Provincial Scientific Research in University of China (No. L2014475) and the Open Subject Fund of the State Key Laboratory of Rolling and Automation of NEU, China (No. 2009003).

\section{References}

[1] Z.B. Wang, Q. Song: Iron and Steel Vol. 36 (2001), p. 66-71

[2] T. Dong, J.Y. Fu: China Metallurgy (2002), p. 16-19

[3] Y. Gan, H. Dong: China Metallurgy (2004), p. 1-6

[4] Z.D. Huang, Q.K. Cai and J.P. Niu: Hot Working Technology Vol. 40 (2011), p. 79-83

[5] T. Senuma: ISIJ Int. Vol. 42 (2002), p. 1-12

[6] G.C. Wang, T.M. Wang and D.L. Shang: Journal of Iron and Steel Research Vol. 19 (2007), p. $5-8$

[7] X.L. Chen: Iron Steel Vanadium Titanium Vol. 23 (2002), p. 11-13 